\title{
Teaching Information Literacy for Lifelong Professional Use
}

\author{
Margrethe B. Søvik * \\ VID Specialized University
}

\begin{abstract}
This paper presents a pilot study carried out in 2015-2016. The main aims of the project was to map information literacy practices among nurses in primary health care and make a summary of previous research focusing on known obstacles. A further aim of the literature review was to identify good solutions and best practice. In spring 2016 a questionnaire was sent out to nurses working in nursing homes in Bergen, Norway. This presentation will outline specificities of IL in the health care context and will then present a few results from the questionnaire connected to this specific context.
\end{abstract}

\section{*Contact:}

Margrethe B. Søvik

VID Specialized University, Campus Betanien, Bergen, Norway

E-mail: margrethe.sovik@vid.no 


\section{Introduction}

After a few years working as a health sciences librarian - with no background in health care and no prior knowledge of the practice field - teaching nursing students, I started asking myself what happens with our students when they finish their education and start working in clinical practice. Do they have the possibility to use what we teach them?

Librarians involved in nursing education spend much time training the students in searching for literature, navigating databases, and evaluating what they find as part of their instruction in information literacy (IL). For instance, I teach nursing students at the bachelor level 8-10 h over 3 years and students in further education programmes 12-15 h over one year. However, as recent studies suggest we do not know much about the transitions from nursing education to working as a clinical nurse and how their training in IL actually is used and implemented in practice (Wahoush \& Banfield, 2014). To find out more about this topic, I applied for funding for a pilot study. This resulted in a one-year project that started in 2015. The Norwegian National Library partly financed the project and it has been carried out in cooperation with Bergen municipality.

\section{The healthcare context: Evidence-based practices and information literacy}

Library instruction in the healthcare professions differs somewhat from instruction to students in other professional contexts. Nurses are expected to be able to work in accordance with evidence-based practice (EBP). In short, EBP consists of three interlinked elements: best research evidence, clinical experience and patient values where the aim is to provide every single patient with the best possible health services. EBP is a dominant paradigm within nursing education, and librarians and faculty teach nursing students according to this model. Ideally, students will now be able to work according to evidence-based practices when they go out in clinical practice after graduation.

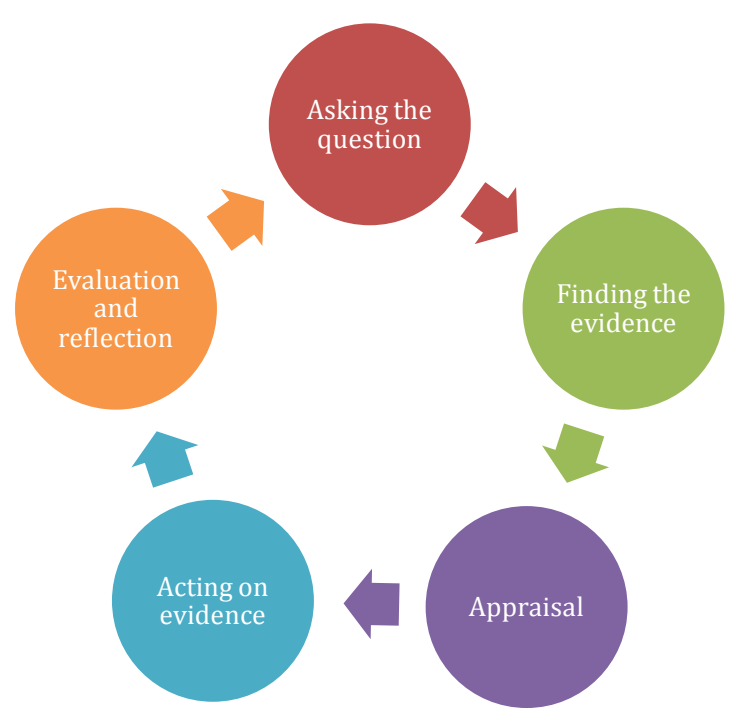

Figure 1: The five steps of EBP

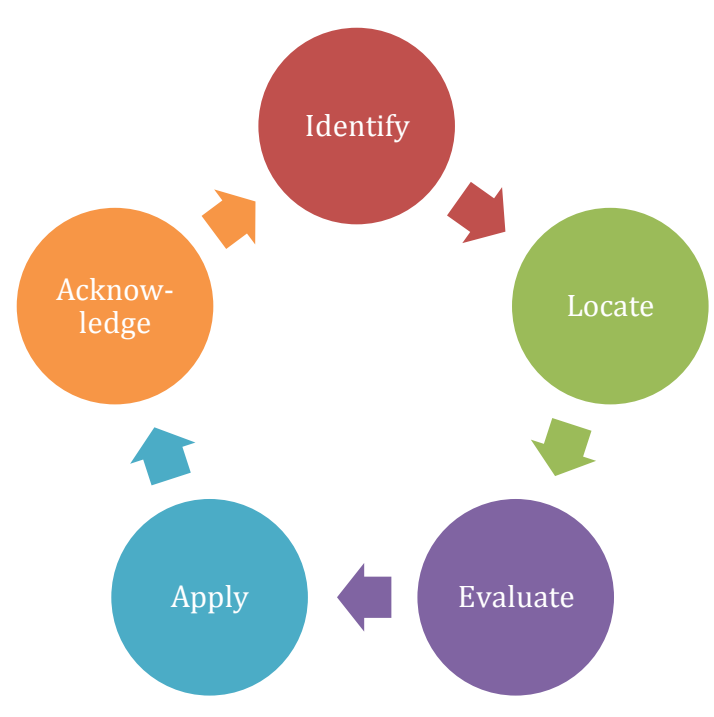

Figure 2: The process of IL

Figures 1 and 2 show how the processes of EBP (to the left) and IL (to the right) are often presented. They are quite similar and cover many of the same themes. This also shows why IL is considered as essential for being able to work within evidence-based practice.

The goal that nurses should work evidence-based and keep updated in a lifelong learningperspective, is formulated in many countries' demands to registered nurses, e.g. in the UK, in 
Canada, and in New Zealand. The ethical guidelines for nurses in Norway (Norwegian Nurses' Organisation, 2011) say that:

1.1 Nursing shall be based on research, experience-based competence and user knowledge.

/.../

1.4 The nurse keeps updated on research, development and documented practice within

his/her own area of work, and contributes to the application of new knowledge in

practice.

\section{A review of previous research}

Several previous researches focus on educational interventions relating to IL. When it comes to identifying best practice it is clear that it is important to have close cooperation between faculty and librarians, and in health this is now quite common and institutionalised. Moreover, "coteaching" is also a model that is used in health/nursing education where librarians and nurse educators teach and supervise together. Another and more demanding model is represented by variants of workplace learning where the librarian is very much involved (Miller, Jones, Graves, \& Sievert 2010; Nordsteien, Horntvedt, \& Holmen 2013; Foss, Kvigne, Larsson, \& Athlin 2014; Kolstad, 2015).

Previous studies have concentrated on EBP and implementation (Foss et al., 2014; Aglen, 2016) but the review of previous research also identified certain research gaps that are of interest for this pilot: There is a limited amount of research on nursing education in relation to IL and EBP (Stombaugh et al., 2013). There is also limited research about IL in the transition from nursing education to clinical practice (Wahoush \& Banfield, 2014) and longitudinal studies covering this theme. It is also claimed to be limited knowledge about how nurses experience IL (Forster, 2013, 2015). Moreover, a study by Younger (2010) concludes that we need further research into the difference between the idealised academic model of searching and real world practicalities, and a recent review (Aglen, 2016) concludes that despite IL being emphasized as a most important part to EBP, "nursing students still struggle to see the relevance of evidence for nursing practice" (p. 261).

In conclusion, previous research shows that we face certain - overlapping - transitional gaps that may be problematic when nursing students meet clinical practice:

- Education vs work life

- Academisation vs clinical practice

- Theory/ideals vs reality

- Evidence-based practice vs actual practice

- And finally: The library vs the practice field. Inskip (2015) calls this a semantic gap. Do others understand what we are talking about when we talk about "information literacy", do we communicate clearly how this may be useful in "real life"?

Moreover, previous research on IL in workplaces points out that IL differs from an educational to a workplace setting (Lloyd \& Williamson, 2008), which is why it is important to bridge the gap between nursing education and nursing practices, also when it comes to IL.

\section{The questionnaire}

The questionnaire was sent out in the first week of April 2016, and not all responses have been analysed at the present time, hence this is just a preliminary analysis. The questionnaire was 
sent out to nurses working in nursing homes in Bergen municipality with the assistance of persons in the municipality.

The questionnaire was distributed both electronically and on paper, to maximise the number of responses. There are some limitations and bias that need to be mentioned. Firstly, there are few respondents ( $n=49$ valid answers to date). Many of these have continued education $(80 \%)$ and many work in positions as leaders at some level or have some kind of special responsibility (65\%). However, this bias is also interesting as this means there is a majority of nurses who are supposed to have more responsibility for working evidence-based and keep updated than the average nurse. This also means that most of the respondents have quite recently finished some educational programme, even though they may have a long working experience as nurses.

The questionnaire explored links between IL and EBP, asking questions such as:

- what kind of information they use and need

- what they use it for

- where they seek information

- how often

- which obstacles they meet

\section{Results and discussion}

In this section there will be a brief presentation and discussion of only a few of the results, due to limited space.

Table 1. Have you received instruction in information searching? ( $n=49$, multiple answers possible)

\begin{tabular}{r|c|c|} 
& $\%$ & $\mathbf{n}$ \\
\hline Yes, at the bachelor level & 55,1 & 27 \\
\hline Yes, at advanced level & 46,9 & 23 \\
\hline Yes, at work & 36,7 & 18 \\
\hline No & 12,2 & 6 \\
\hline
\end{tabular}

Table 2. Are you familiar with evidence-based practice (EBP)?

\begin{tabular}{r|c|c|} 
& $\%$ & $\mathbf{n}$ \\
\hline Yes & 75,5 & 37 \\
\hline No & 22,4 & 11 \\
\hline Do not know & 2,0 & 1 \\
\hline Total & $\mathbf{1 0 0}$ & $\mathbf{4 9}$ \\
\cline { 2 - 3 } & &
\end{tabular}


Table 3. Do you work according to principles of EBP at your workplace?

\begin{tabular}{r|c|c|}
\multicolumn{2}{|c}{$\%$} & n \\
\hline Yes & 37,8 & 14 \\
\hline No & 10,8 & 4 \\
\hline Sometimes & 45,9 & 17 \\
\hline Do not know & 5,4 & 2 \\
\hline Total & $\mathbf{1 0 0}$ & $\mathbf{3 7}$ \\
\hline & & \\
\hline
\end{tabular}

Most of the respondents have received instruction in information searching, only 6 persons had not. Also, three quarters said they were familiar with EBP, and of these 75,5\% only 1 in 10 said that they do not work according to principles of EBP at their workplace. However, to go deeper into what "sometimes" actually means, another type of study is needed.

I will present and discuss Tables 4 and 5 together as they also point to some inconsistencies. To perform procedures is clearly the main reason why respondents search for information, but it is interesting to notice that "to be updated" is a good number two, chosen by almost three-quarters of the respondents. However, when we turn to Table 5 and study what kind of sources the respondents say they use the most, and how often they estimate to use them, the picture changes somewhat.

Table 4. 5 top reasons for searching information (multiple answers possible) $(\mathrm{n}=49)$

\begin{tabular}{r|c|c} 
& $\%$ & n \\
\hline To perform a procedure I rarely/never have performed & 83,7 & 41 \\
\hline To be updated (new research and best practice) & 71,4 & 35 \\
\hline General knowledge about patients & 63,3 & 31 \\
\hline Answer questions from patients/relatives & 59,2 & 29 \\
\hline To answer questions from colleagues & 55,1 & 27 \\
& &
\end{tabular}

Table 5. How often do you actively seek information from the following sources? $1=$ daily, $2=2-3$ times/week, $3=$ monthly, 4= 3-4 times/year, $5=$ never

$$
\text { Source n } \begin{gathered}
\text { Frequency } \\
\text { (mean) }
\end{gathered}
$$

\begin{tabular}{|r|r|r|}
\hline Own experience & 33 & 1,7 \\
\hline Ask colleague & 35 & 2,4 \\
\hline
\end{tabular}




\begin{tabular}{r|c|c|}
\hline Google & 36 & 2,5 \\
\hline Ask leader & 36 & 2,7 \\
\hline Local procedures at nursing home & 38 & 2,9 \\
\hline Information from other health institutions & 32 & 3,1 \\
\hline Thespitals, nursing homes) & & \\
\hline National Electronic Health Library & 38 & 3,3 \\
\hline (Helsebiblioteket.no) & & \\
\hline Text books & 34 & 3,3 \\
\hline Journals & 35 & 3,5 \\
\hline NEL (Norwegian medical handbook, available & 36 & 3,7 \\
\hline on internet) & & \\
\hline Practical procedures in Nursing (PPS) (not & 38 & 3,8 \\
\hline available to all respondents) & & \\
\hline Fagrosedyrer.no (procedures on the internet) & 34 & 4,1 \\
\hline
\end{tabular}

We can see a tendency here which is similar to what other studies find: intrapersonal sources first, and text-based and research-based sources last. These different sources have been colour-coded according to type of source. The green, intra-personal sources are used the most and some of the yellow procedures are consulted relatively often. This corresponds to what respondents answered to the question of why they search for information. However, it seems that some of the more evidence-based sources are used quite seldom, even though "to be updated" as a reason for searching for information is mentioned by $70 \%$ of the respondents (as seen in Table 4).

However, it is also interesting when asking why respondents do not search for information. Here, "I do not have the time to search" is stated as the number one reason for most respondents $(\mathrm{n}=12)$ and compared with previous studies this is not surprising, it is a most common obstacle to searching for information. But "I search often enough" is second in place, stated by 11 persons, and this is mentioned by more people in total when adding up the top 3 reasons for not searching for information (22 answered "I search often enough" and 19 answered "I do not have the time to search"). This becomes even more interesting when these figures are compared to frequencies of searching as seen in Table 5 above, as it seems that information searching is not carried out on a very frequent basis. Resources that we would expect them to use, e.g. the Norwegian Electronic Health Library, are used quite seldom. Hence, it seems the respondents have a clear conception of why they should search for information, but that this may not be carried out in practice. However, why this is so, must be examined in a further study.

\section{Conclusions}

This short presentation of a pilot study consisting of a literature review and a questionnaire ends in identifying a few challenges and some questions for further research. 
In the practice field/workplaces the experience is that time is still a problem, and lacking access to technical equipment (i.e. tablets, wifi) still represents a challenge. However, we do not know enough about workplace culture - it may be interesting to continue with a fieldwork of more ethnographic character. How often and in which situations do they work "evidencebased"? Why is it that the respondents feel that they search enough? According to which standards and expectations may this be seen to be enough? Also, we need to explore further which available resources are not being used and why. For instance, the respondents claim to be familiar with the Norwegian Electronic Health Library (www.helsebiblioteket.no) but they do not use it much, are such resources not experienced as relevant or sufficiently helpful?

In education and more specifically library instruction we need to focus even more on instruction that is experienced as relevant and find good examples, best practices and role models. To do this we need better contact and cooperation with the practice field. More specifically, how do we reach out to the ones not taking further education? A more concrete lesson learnt from this project is to acknowledge a wider variety of sources and incorporate new types of sources, e.g. procedures found on YouTube. 


\section{References}

Aglen, B. (2016). Pedagogical strategies to teach bachelor students evidence-based practice: A systematic review. Nurse Education Today, 36, 255-263. doi: 10.1016/j.nedt.2015.08.025

Forster, M. (2015). Six ways of experiencing information literacy in nursing: The findings of a phenomenographic study. Nurse Education Today, 35(1), 195-200. doi: 10.1016/j.nedt.2014.06.005.

Forster, M. (2013). A phenomenographic investigation into information literacy in nursing practice: Preliminary findings and methodological issues. Nurse Education Today, 33(10), 1237-1241. doi: 10.1016/j.nedt.2012.05.027

Foss, J. E., Kvigne, K., Larsson, B. W., \& Athlin, E. (2014). A model (CMBP) for collaboration between university college and nursing practice to promote research utilization in students' clinical placements: A pilot study. Nurse Education in Practice, 14(4), 396-402. doi: 10.1016/j.nepr.2013.11.008

Inskip, C. (2015). Making information literacy relevant in employment settings. Online Searcher, 39(4), 54-57.

Kolstad, A. K. (2015). Co-teaching in information literacy during work placements: The librarian's role. LIBER Quarterly, 25(2), 56-86. doi: 10.18352/lq.10049

Miller, L. C., Jones, B. B., Graves, R. S., \& Sievert, M. C. (2010). Merging silos: Collaborating for information literacy. Journal of Continuing Education in Nursing, 41(6), 267-272. doi: 10.3928/00220124-20100401-03

Nordsteien, A., Horntvedt, M-E. T., \& Holmen, N. T. (2013). The development of a model for teaching information literacy to nursing students through cross-professional collaboration. Nordic Journal of Information Literacy in Higher Education, 5(1), 32-37.

Norwegian Nurses' Organisation (2011). The ethical guidelines for nurses. Retrieved from https://www.nsf.no/Content/785285/NSF-263428-v1-YER-hefte_pdf.pdf

Lloyd, A., \& Williamson, K. (2008). Towards an understanding of information literacy in context: Implications for research. Journal of Librarianship and Information Science, 40(1), 3-12. doi: $10.1177 / 0961000607086616$

Stombaugh, A., Sperstad, R., Vanwormer, A., Jennings, E., Kishel, H., \& Vogh, B. (2013). Using lesson study to integrate information literacy throughout the curriculum. Nurse Educator, 38(4), 173-177. doi: 10.1097/NNE.0b013e318296db56

Wahoush, O., \& Banfield, L. (2014). Information literacy during entry to practice: Informationseeking behaviors in student nurses and recent nurse graduates. Nurse Education Today, 34(2), 208-213. doi: 10.1016/j.nedt.2013.04.009

Younger, P. (2010). Internet-based information-seeking behaviour amongst doctors and nurses: A short review of the literature. Health Information and Libraries Journal, 27(1), 2-10. doi: $10.1111 / \mathrm{j} .1471-1842.2010 .00883 . x$ 